\title{
Land Use and Climate Impacts on Fluvial Systems during the Period of Agriculture (LUCIFS)
}

Cumulative Global Change is occurring by the removal of forests, conversion to cultivation of marginal land, and intensification of cultivation. Systemic Global Change, in the form of climate change and atmospheric chemistry change, is likely to alter land use patterns during the next century. All of these changes will affect rivers and their catchments, altering flows of water, sediment, nutrients, carbon and pollutants. Past changes of land and climate are still being felt in many catchments, and are difficult to understand without a historical perspective. Future changes, when superimposed on changes triggered in the past, will produce complex responses which will be difficult to anticipate.

There is therefore a clear need for a better understanding, and a better theory, of fluvial system response to land use and climate change, to anticipate and perhaps predict future changes, and to understand current dynamics. While most scientific research has been conducted in small catchments, most interest in future responses is in large catchments. The time period over which a large catchment responds to land use or climate change is much longer than is the case for a small catchment; much longer than most instrumental time series. Therefore, the paleoenvironmental record provides a unique data repository of catchment responses, fully realised over decades to centuries. This repository, or library, is an unparalleled set of experiments already carried out. Our task is to exploit this library.

The PAGES-LUCIFS Project aims to assemble a library of fluvial system responses from around the world, using case studies selected to represent both the modern array of land use and catchment types, and the areas where land use has evolved slowly over millennia and where industrial agriculture has been transplanted to non-agricultural landscapes during the last few centuries. Modelling of this library of responses is being developed to provide the tools for anticipation and/or prediction of future change.

While Global Change impacts on fluvial systems are important, change to these systems will also affect the coastal zone by increasing the flow of materials to the coast, in some cases, and decreasing flows in other cases. The changed transport of carbon and nutrients by rivers also have a role in global biogeochemistry, particularly in the coastal zone.

Rivers therefore play a role as one of the links between the major global biogeochemical systems, but, more than that, they are crucially important to human well being and for many aquatic organisms. The importance of fluvial systems, as phenomena that are affected by Global Change and affect Global Change, is clear, along with their enormous societal and ecological significance.

The LUCIFS planning group has identified five key questions to guide research, as follows:

1. What is the sensitivity to climatic change of the spatial distribution of sediment, $\mathrm{P}$ and $\mathrm{C}$ fluxes in different climate/vegetation regions?

2. How do sediment, $\mathrm{P}$, and $\mathrm{C}$ flux sensitivities to land use under climatic shifts reflect stages of land use history?

3. How are fluvial system response sensitivities under various land uses influenced by the direction of climatic change?

4. What are the thresholds and response and recovery of fluvial systems for different combinations of land use and climatic change?

5. How do engineering and other human-related modifications, including dams and reservoirs, levees, channel morphology alteration, and wetland drainage enhance or suppress climatic impacts on sediment, $\mathrm{P}$, and $\mathrm{C}$ fluxes in various climate/ vegetation regions?

In summary, these questions revolve around the sensitivity of fluvial systems to land use and climate change, both individually and in concert. To answer these questions globally, case studies from various parts of the world are needed.

A LUCIFS workshop is being planned for January 1999. The workshop will have the following purposes:

Review progress to date by each group presenting its scientific results and plans for the future.

1. Review progress in modelling

2. Assemble major conclusions that can be reached at this stage in the project, possibly to produce a multi-authored paper for an international journal.

3. To agree on research protocols and modelling strategies to ensure that future work is comparable and useful for the LUCIFS objectives.

Copies of the LUCIFS Project Implementation plan (R.J. Wasson ed, 1996 Land Use and Climate Inputs on Fluvial systems During the Period of Agriculture, PAGES Workshop Report, Series 96-2, 51pp) are available from the PAGES International Project Office. The first LUCIFS newsletter, from which the text of this article has been drawn, is available on-line at http://www.pages.unibe.ch/publications/ publications.html.

\section{BoB WAsson}

Geography Department, Australian National University, Canberra 0200, Australia

robert.wasson@anu.edu.au

\section{Second Workshop on Global Paleoenvironmental Data}

\author{
Boulder, CO, USA, February 9-12, 1998
}

Putting individual paleorecords into a multi-proxy, multi-disciplinary, global context is the only way to synthesize a truly global picture of past climatic and environmental change. The difficulties inherent in synthesizing research across-disciplines and between countries are well known, but not insurmountable. Many of the past successes in paleodata management, including the hotoff-the-presses Greenland Ice Core Data CD, Ocean Drilling Program Database, International Tree Ring Data Bank, and North American and European Pollen Databases have understandably been organized independently, primarily along disciplinary and geographical lines. This workshop brought together data management experts from 43 different PAGES data efforts in an attempt to produce an implementation plan for a broad set of guidelines on how to set up a regional or thematic data effort.

One of the principle conclusions of the group was the necessity for making databases consistent in terms of their required documentation and formats. Databases need to be useful to people from outside the field, who may wish to extract information for comparative purposes without excessive complications. At the same time they should serve the needs of scientists who require a detailed accounting of the raw data, any methods used to filter the data and the manner in which climatic or environmental information has been inferred from the data as well as a careful quantification of the uncertainties. It was agreed that the primary responsibility for proper interpretation of archived data lies with the individual users, just as the ultimate quality of the archived data rests with the individual contributors. Nonetheless, effort should be made to structure and maintain databases so as to maximize ease of access and submission and at the same time minimize potential pitfalls of data misinterpretation.

The group took as its starting point the World Data Center System Guide, published by the International Council of Scientific Unions in 1996, and the Global Paleoenvironmental Data report (PAGES report 95-2), which arose out of the first PAGES data workshop held in 1993. Although these documents provide an admirable foundation, the world of data management has blossomed exponentially in the past decade and an update is required. A two part report entitled "The PAGES Data Guide" is being prepared by the 
meetings co-conveners David Anderson and Robin Webb with input from all of the attendees. The first part will primarily consist of a compendium of data centers within PAGES and in overlapping fields. The second part will present guidelines on how to set up a regional or topical data center. Although the document will be produced in hardcopy, available from the WDC-A in Boulder and the PAGES IPO in Bern, it will also be put on the PAGES and WDC-A Internet sites, where it will be maintained more dynamically and thus remain an invaluable research tool into the future.

For more information on the evolving PAGES Data Guide contact David Anderson (dma@paleosun.ngdc.noaa.gov) or look for updates on the PAGES and WDC-A web sites (http:/ / www.pages.unibe.ch/ and http:// www.ngdc.noaa.gov/paleo/paleo.html).

\section{Keith Alverson}

PAGES IPO, alverson@pages.unibe.ch

\section{PEP1: Paleoclimate of the Americas}

Merida, Venezuela, March 16-20, 1998

Over seventy scientists from all over the world, studying paleoclimate from Argentina to Alaska, assembled to address interhemispheric linkages in past climatic and environmental change in the Americas. The meeting began with a session on the human dimensions of climate change, a topic well deserving of this prime time billing given that the Americas transect, and in particular the Andes region, has seen an intricate interplay of human habitation and environmental change for over ten thousand years. The rise and fall of pre-Colombian civilizations in coastal regions, lowlands and the Andes were measured alongside records of pollen assemblages, lake level reconstructions, volcanic history and levels of snow deposition on high altitude glaciers. The interplay of technological, economic and social changes with environment and climate did not end in the distant past. In more recent decades, urbanization and poverty have dramatically effected local ecosystems and at the same time led to increases in the human vulnerability to environmental change.

Discussion of Holocene climate variability in the Americas was understandably dominated by the influence of El-Niño, the signal of which was discussed in records as diverse as Andean lake levels, Galapagos corals, tree rings and historical accounts. In the late glacial session an issue which permeated many of the talks was synchroneity of the Younger Dryas.
Ageneral consensus was reached that the term 'Younger Dryas' describes a European event and should not be forced upon the rich tapestry of climate variability which is being uncovered in the Americas like a square peg into a round hole. Interhemispheric comparisons of Greenland and Antarctic ice core records seemed to indicate that the temperature anomalies are out of phase, such that the Antarctic Cold Reversal coincided with the Allerod-Bolling warming and anomalous warmth in the Antarctic coincided with northern hemisphere cool periods associated with Dansgaard-Oeschger variability. Ocean data were presented which seemed to support these ice core results, in addition to suggesting perhaps a slight southern hemisphere lead. The monkey wrench thrown in this picture was the recent Taylor Dome record, from a coastal Antarctic site, which appears to match the Greenlandic and not the Antarctic pattern. Polynyas were suggested as one possible cause for this anomalous record. The full glacial session centered around re-evaluation of tropical temperature changes during the Last Glacial Maximum and the climatic effects of changes in the ocean thermohaline circulation.

A more detailed reporting of the PEP1 meeting will appear in a future PAGES newsletter. A limited number of extended abstract volumes and further information on PEP1 programs are available from Vera Markgraf (markgraf@spot.colorado.edu). The full meeting program can be found at http:// instaar.colorado.edu/misc/pep.html.

\section{Keith Alverson}

PAGES IPO, alverson@pages.unibe.ch

\section{ScanTran}

\section{Rovaniemi, Finland, March 19-23, 1998}

ScanTran is the name adopted for the IGBP high latitude terrestrial transect (Koch et al., 1995) through Scandinavia and northern Europe. The workshop in Rovaniemi represented the third in a series of workshops leading to the development of the ScanTran Science Plan that will be submitted to IGBP later this year. The initial workshop in Høvik (April 1996) was organised by the Norwegian IGBP Committee; as a result of the positive response of participants in that workshop to the proposal to develop an integrated science plan for a Fennoscandian terrestrial transect a second workshop was organised. This second workshop, held in Trondheim (June 1996), developed a clear outline of the science plan for the transect, and produced a report (Heal et al., 1997) identifying both the key features of the proposed transect and the foci for the proposed integrated research programme. The
Rovaniemi meeting was an open meeting to which a wide international audience of scientists and social scientists was invited. The objectives of the meeting were to inform this wider audience about ScanTran, to confirm in greater detail the objectives of the proposed long-term programme of research in order to produce the Science Plan for submission to IGBP, and to identify individuals who would carry forward the process of establishing ScanTran as a recognised IGBP high latitude transect.

Some 90 or so participants registered for the meeting. Although registration was strongly biased towards the terrestrial ecology (GCTE) community, other IGBP core projects were also clearly represented (BAHC, IGAC, PAGES). One session of the formal presentations to the meeting was dedicated to Past Changes, with a keynote presentation by Brian Huntley and Richard Bradshaw that explored some of the key evidence of Holocene environmental and ecological changes in the ScanTran region, and an invited presentation by Matti Eronen that discussed especially the dendroclimatological evidence for Holocene and recent climatic and other environmental changes in northern Fennoscandia. A series of offered papers then discussed a wide range of paleoenvironmental topics. One of the Working Groups during the workshop sessions also was dedicated to Past Changes; the report from this Working Group will form part of the report from the meeting as a whole that is due to be published later this year. This report also will include extended abstracts of the papers presented at the meeting.

The meeting recognised a number of important features of the region encompassed by ScanTran that give added strength to the proposed terrestrial transect study. Amongst these, the established network of research sites with field stations and infrastructure to support field research is a key asset. Similarly, the existence of a large body of existing knowledge that can underpin any new research initiatives is of very great value; such knowledge includes, in the PAGES context, data from ice cores, from sediments both of the surrounding ocean basins and of lacustrine basins in the region, from studies of peat deposits, from dendroclimatological investigations and from archaeological studies at sites within the region. The long-term presence of human populations in the region, and the records of their impacts both from archaeological studies and from research into their indigenous knowledge, are a special feature of this region that will differentiate ScanTran from the other IGBP high latitude transects. The complementary environmental gradients of latitude and continentality also are a special feature of this region. These

continued on page 16 